\title{
Monitoring and analysis of vertical thermal structure of the Three Gorges Reservoir
}

\author{
Dai Lingquan ${ }^{1,2,3^{*}}$, Liu Haibo ${ }^{2}$, Li Wei ${ }^{1}$, Tang Zhengyang ${ }^{2}$, and XuYang ${ }^{2}$ \\ ${ }^{1}$ China Three Gorges Corporation, Beijing, 100038, China \\ ${ }^{2}$ Three Gorges Cascade Dispatching and Communication Center, China Yangtze Power Corporation, Yichang, 443002, China \\ ${ }^{3}$ College of Hydraulic and Environmental Engineering, China Three Gorges University, Yichang, 443002, China
}

\begin{abstract}
Water temperature plays a crucial role in water ecological environment both in the reservoir and downstream area. Three Gorges Project (TGP) is the largest hydraulic engineering in the world, and changes of water quality attract much more attention, especially in the thermal structure since impoundment. In order to clearly understand water temperature distribution after impoundment in the Three Gorges Reservoir (TGR), we monitored the temperature distribution of the Taipingxi section which was not far from the dam from early April to the end of July. According to the analyzing of the monitoring data of transverse and vertical temperature variation, we could find that the temperature mixed uniformly in transverse direction. Excepting April, there was basically had no temperature difference in vertical direction, even in April, the maximum temperature difference was only $1.39^{\circ} \mathrm{C}$ within 100 meters (April 22), the average temperature gradient was only $0.014^{\circ} \mathrm{C} / \mathrm{m}$; Both the temperature of water and atmosphere have similar variation tendency, but the response of the water temperature to atmosphere is delayed, especially the bottom water temperature. The result indicate that the reservoir has mixed thermal structure during impoundment phase, so the release temperature had little change after the impoundment, the work provide a scientific basis for the development of pollution control and ecological protection measure.
\end{abstract}

\section{Introduction}

Water temperature is an important water quality parameter in aquatic ecosystems, and plays a crucial role in ecological functioning and controlling the biogeochemical processes of a water column ${ }^{[1-3]}$. Most deep temperate and subtropical reservoirs develop thermal stratification every spring and summer ${ }^{[4]}$. the stable stratified water column is usually segregated into epilimnion, thermocline and hypolimnion in vertical by the density difference produced via warming of surface water, stratification acts as a barrier restraining mixing of the water column, as a result of incomplete mixing of the water column and lack of light for the photosynthesis at the hypolimnion, the water column can become anoxic ${ }^{[5-6]}$. Commonly, many reservoirs have fixed-level "off-takes" that are situated below the thermocline, hence releasing waters from the hypolimnion which causes downstream cold-water pollution $(\mathrm{CWP})^{[7]}$. The CWP is thought to be a key threat to a number of species, primarily due to the importance of warm-water temperature for important life stages, therefore, penetratingly understanding of temperature structure in reservoirs is one of the important contents in water quality assessment of hydropower project $^{[8]}$.

TGP is a key to the Yangtze River management and development which is constructed from 1994 to 2009; It brings significant benefits in electric power generation, flood control and shipping traffic et al, and the TGR is a large temperate reservoir located in the mid-west of China, spans Hubei province and Chongqing municipality, with a surface area of $79000 \mathrm{~km}^{2}$ and a storage capacity of $3.93 \times 10^{10} \mathrm{~m}^{3}$ at his maximum water level $(175 \mathrm{~m})$. The dam is deep-release dam which is located at the east most part of the reservoir, controlling the outflow of the Yangtze River, the outlets locate between $97 \mathrm{~m}$ to $104 \mathrm{~m}$, correspondingly, we refer them as deep outlets, 32 unit of turbine each of them in capacity of $700 \mathrm{MW}$ and in total $2.24 \times 10^{7}$ megawatts are installed in power generation section of dam ${ }^{[9-10]}$.

Impoundment in the TGR is composed of 4 stages: (1) to the water level $135 \mathrm{~m}$ June 1, 2003 to June 10; (2) to water level $139 \mathrm{~m}$ on November 5, 2003; (3) to $156 \mathrm{~m}$ on October 27, 2006; (4) during the last stage, water level reaches $175 \mathrm{~m}$ in 2009. In 2003, TGR began to initially impound and generate electricity, the water level reached $135 \mathrm{~m}$ on June 1 , then $139 \mathrm{~m}$ on November 5 for benefits in shipping traffic and electric power generation. Before impoundment, water level fluctuated between 70 to $80 \mathrm{~m}$ at the dam site, but it raised more than $60 \mathrm{~m}$ since impoundment, as a result, velocity in reservoir area decreased, the residence time of the water body prolonged, it was not conducive to the degradation of pollutants, suspended pollutants settled easily, so the capability of water exchange was weakened ${ }^{[10]}$, the thermal structure of

\footnotetext{
*Corresponding author: dai_lingquan@163.com
} 
the reservoir might be different from the original channel before impoundment, so the changes of water quality and eco-environmental caused by impoundment had been a topic of wide concern.

In order to clearly understand the water temperature distribution after impoundment, We monitored the temperature distribution of the section Taipingxi near the dam which entrusted by China Three Gorges Corporation, Yangtze Valley Water Environment Monitoring Centre.

In this paper, many of monitoring data including water temperature, discharge, water level, meteorology were collected and collated, characteristic of thermal structure along the transverse and vertical direction in Taipingxi section which was in front of the dam were analyzed as well as the relationship between the water temperature and air temperature, based on the analysis, some suggestions to the further study were also put forward.

\section{Materials and methods}

\subsection{Monitoring Section}

The thermal structure in front of dam has a critical influence on the release temperature, so the choice of monitoring section is very important. In this study, the monitoring section is Taipingxi, which is located at the main Yangtze River channel, about $4000 \mathrm{~m}$ away from the dam, see Figure 1.

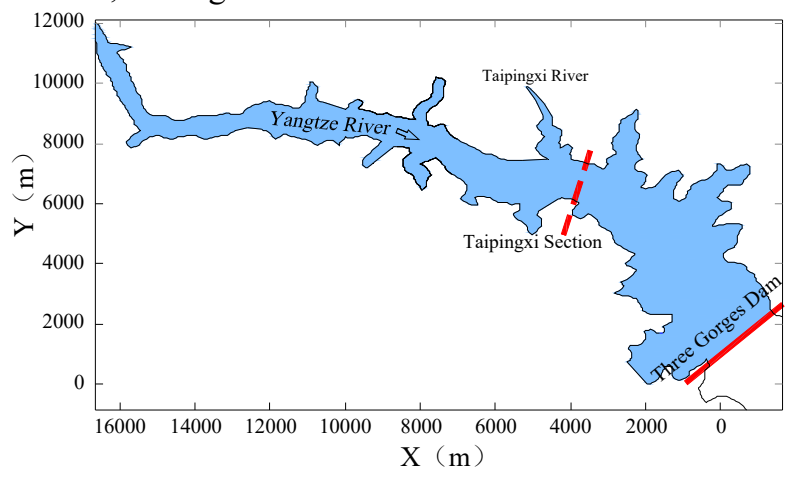

Fig. 1. General layout of Taipingxi section

\subsection{Placement of Vertical Lines and Monitoring Sites}

Monitoring projects include temperature distribution along the transverse direction and vertical direction, air temperature. Five to seven vertical lines were set in the section, from the left bank to right, their labels were "L1" , "L2" ,.., "M",..., "R2", "R1", among them, "L" meant lines located in the left bank, and " $R$ " in the right bank, "M" meant the middle line. Monitoring values of the same depth from different vertical lines represents the water temperature along the transverse variation.

Along the vertical direction, profiles of temperature were available from surface to bottom at the section: for upper water, data were collected at 0.2, 0.5, 1.0, 2.0, 5.0, 8.0 depths, respectively; for deep water (water depth $>10$ $\mathrm{m})$, data were collected with a vertical interval of $5.0 \mathrm{~m}$, because there was no significant difference for temperature variation. In post-processing phase, average temperature of the same depth from different lines represented the value in this depth.

\subsection{Monitoring Time}

The most likely opportunities for thermal stratification are in spring and summer when direct solar radiation and increased air temperatures heat surface layers faster than deeper layers. During this period, flood season is not coming, discharge is not abundant enough, the operating water level of the reservoir gradually reduces because a substantial amount of water will be discharged for forthcoming flood season, besides, solar radiation and temperature rise gradually, and this is one of important factors of stratification, so we select the monitoring time from April to July after impoundment, and the frequency is three times a month. Hydrolab water quality parameters instrument which could continuously monitor temperature along depth was used to monitor water temperature.

\section{Reuslts and Discussion}

\subsection{Transverse Water Temperature Variation}

Figure 2 to Figure 5 shows temperature distribution along transverse direction from different vertical lines on April 22, May 19, June 15, July 16, the figures show that in transverse direction, temperature difference is very small, often less than $0.5^{\circ} \mathrm{C}$, the reasons of this phenomenon is that: the reservoir is narrow-deep type, velocity in longitudinal direction is much larger than that transverse direction, so the water mixed homogeneously in this direction, for river- type reservoir such as TGR, temperature variation often occurred in longitudinal and vertical direction when the reservoir operates normally.

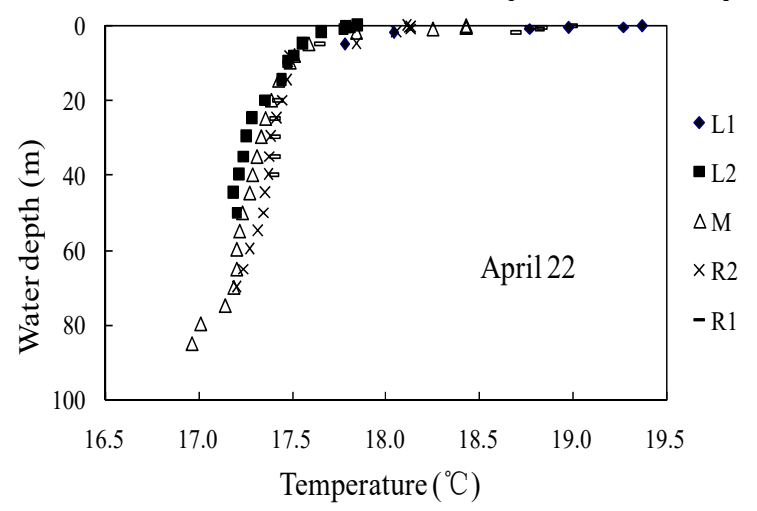

Fig. 2. Temperature variation along transverse direction from different vertical lines on April 22 


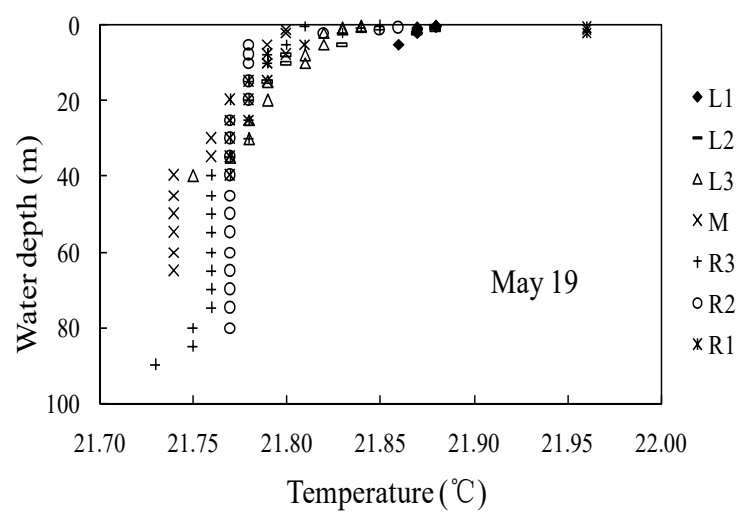

Fig. 3. Temperature variation along transverse direction from different vertical lines on May 19

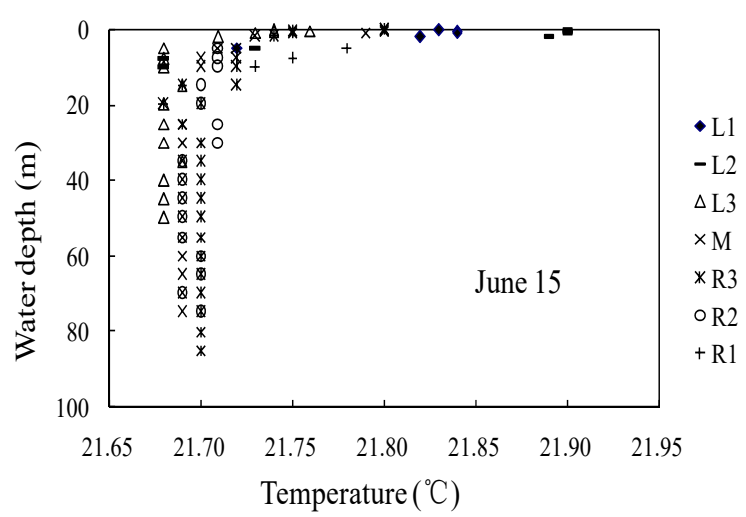

Fig. 4. Temperature variation along transverse direction from different vertical lines on June 15

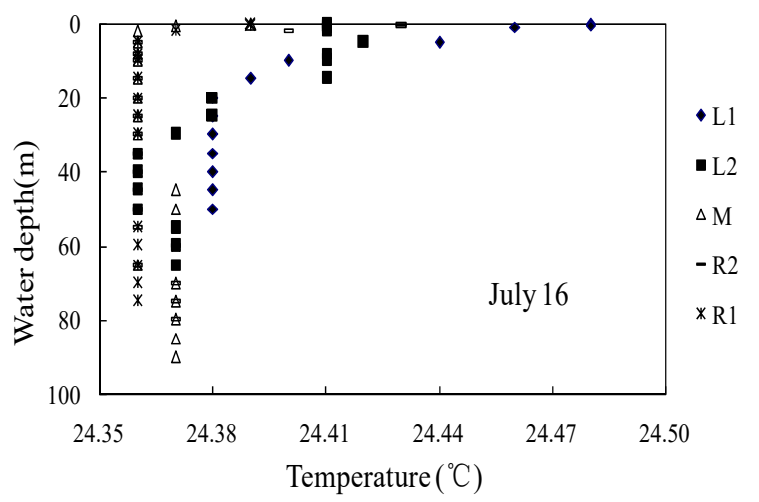

Fig. 5. Temperature variation along transverse direction from different vertical lines on July 16

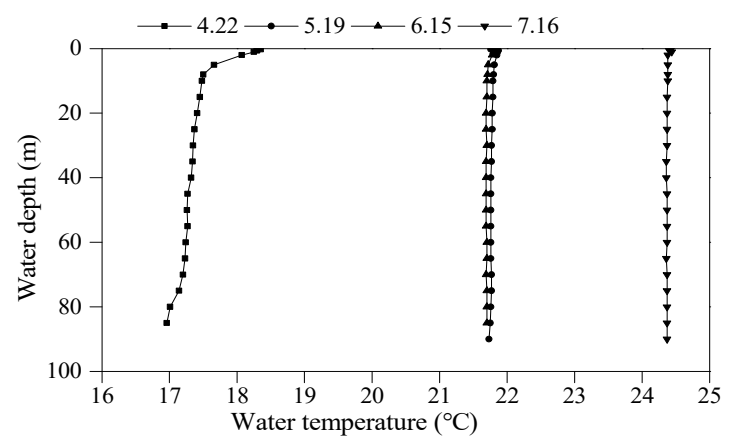

Fig. 6. Vertical temperature variation from April to July

\subsection{Vertical Temperature Distribution}

The vertical water temperature distribution from April to July is shown in Figure 6. From the figure can clearly see that vertical temperature distribution is basically the same in different depth, it has no apparent stratification from early April to the end of July, no metaimnion, no hypolimnion, both the surface and bottom temperature increased with the rising of the air temperatures, but the relationship between the surface and the air temperature was more obvious, so the temperature of surface water was slightly higher than deep water when the discharge was not abundant enough. From the surface to the bottom water temperature slightly decreased, and had a weak temperature gradient in April, but the maximum temperature difference was only $1.39^{\circ} \mathrm{C}$ within 100 meters, the average temperature gradient was $0.014^{\circ} \mathrm{C} / \mathrm{m}$ correspondingly, but this phenomenon disappeared as the air temperature continues to rise, and basically mixed homogeneously from May to April in vertical.

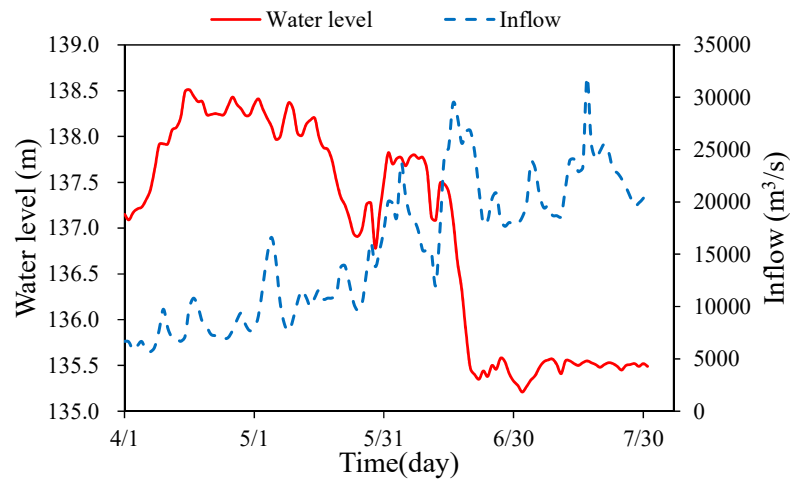

Fig. 7. Variation of water level and inflow during the monitoring time

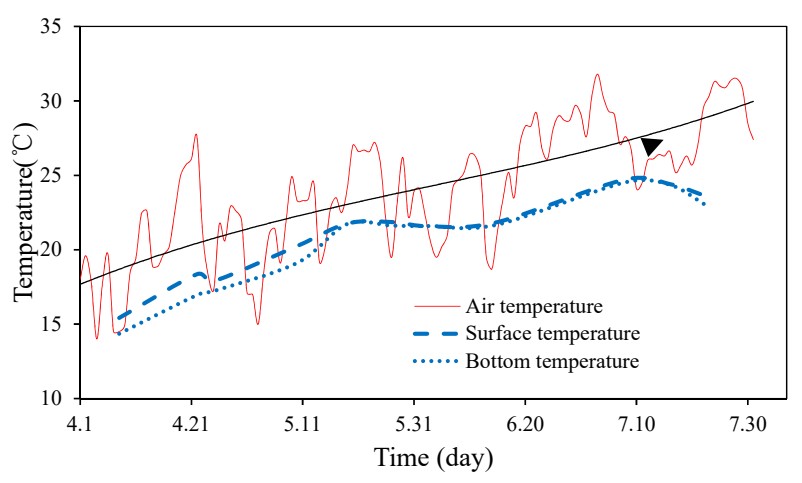

Fig. 8. Discharge, air temperature, surface temperature, bottom temperature during the monitoring time

\subsection{Effects of Hydrodynamic Conditions on Temperature}

Hydrodynamic conditions including inflow and water level have directly influence on thermal structure both in longitudinal and vertical direction, before flood season in June, the variation of the inflow was small, in order to give full play to power generation, the water level maintained at high level as much as possible (Figure 7), as a result, water mixed not uniform slightly, surface temperature was a little higher than the bottom. on June 
1, the hydrodynamic conditions played a leading role when the inflow was suddenly increased, both the surface and bottom kept at the same temperature

\subsection{Relationship between Water and Air Temperature}

Air temperature is another important factor for the reservoir temperature distribution; the reservoirs which develop thermal stratification often locate in temperate or subtropical zone where the air temperature is high in several months or seasons. During the process of water temperature observation, air temperature was also monitored simultaneously; Figure 8 shows the variation processes of air temperature, surface temperature, bottom temperature. Water temperature increase in the same trends with air temperature, both the water temperature at surface and bottom rise with air temperature, but the response of the water temperature to atmosphere is delayed. Surface water is directly contact with the upper atmosphere, and absorb solar radiation energy, so the temperature at surface is a little higher than the bottom when the inflow is not abundant enough before June.

In general, compared with the air temperature variation, changes in water temperature delayed almost a month. That specific heat capacity of water is higher than atmosphere is also another reason that water temperature changes in amplitude is also less than that of atmosphere.

\section{Conclusions}

In order to get detailed information about the thermal structure in the TGR for researches on impacts of initial impoundment on water quality, we implemented a series of monitoring work at Taipingxi section in front of the dam, from the above analysis, the following conclusions can be reached.

(1) Because the Taipingxi section locates in front of the dam, also close to the dam, this area is most vulnerable to develop stratification in TGR, and water temperature in this section mixed homogeneously most of the time, so we can infered there had no phenomenon of stratification during the initial impoundment phase when water level arrived $135 \mathrm{~m}$ and $139 \mathrm{~m}$, the most possible direct reason was that although the velocity slowed after impoundment, but upper and bottom water still could mix sufficiently with the aid of turbulent motion .

(2) The variation trends of the air temperature and water temperature are coincident, but compared to the air temperature, variation in water temperature delayed almost a month, especially the bottom before the coming of flood season.

(3) Despite of the reservoir had no stratification when water level arrived $135 \mathrm{~m}$ and $139 \mathrm{~m}$, also had no influence on ecological environment of downstream, but this did not mean that when water level arrived $156 \mathrm{~m}$ or $175 \mathrm{~m}$ with the normal operation of the project, the water still had no stratification, so we need further observation and research on the thermal structure when the projects operate at high stage.

\section{Acknowledgments}

This work was funded by the Engineering Research Center of Eco-environment in Three Gorges Reservoir Region, Ministry of Education, China Three Gorges University Open Research Program (KF2016-08).

\section{References}

1. Chang T, Gao X, Danley PD, et al. Longitudinal and temporal water temperature patterns in the Yangtze River and its influence on spawning of the Chinese sturgeon (Acipenser sinensis Gray 1835)[J]. River Research and Applications, 2017,33(9): 1445-1451.

2. Clancey K, Saito L, Hellmann K, et al. Evaluating Head-of-Reservoir Water Temperature for Juvenile Chinook Salmon and Steelhead at Shasta Lake with Modeled Temperature Curtains[J]. North American Journal of Fisheries Management, 2017,37(5): 1161-1175.

3. Farasat A, Sefti MV, Sadeghnejad S, et al. Effects of reservoir temperature and water salinity on the swelling ratio performance of enhanced preformed particle gels[J]. Korean Journal of Chemical Engineering, 2017,34(5): 1509-1516.

4. Niemeyer RJ, Cheng Y, Mao Y, et al. A Thermally Stratified Reservoir Module for Large-Scale Distributed Stream Temperature Models With Application in the Tennessee River Basin[J]. Water Resources Research, 2018,54(10): 8103-8119.

5. Arthington AH, Kennen JG, Stein ED, et al. Recent advances in environmental flows science and water management-Innovation in the Anthropocene[J]. Freshwater Biology, 2018,63(8): 1022-1034.

6. Maloney KO, Cole JC, Schmid M. Predicting Thermally Stressful Events in Rivers with a Strategy to Evaluate Management Alternatives[J]. River Research and Applications, 2016,32(7): 1428-1437.

7. Zou J, Rezaee R, Liu K. Effect of Temperature on Methane Adsorption in Shale Gas Reservoirs[J]. Energy \& Fuels, 2017,31(11): 12081-12092.

8. Lewis WM, Jr., Mccutchan JH, Jr., Roberson J. Effects of Climatic Change on Temperature and Thermal Structure of a Mountain Reservoir[J]. Water Resources Research, 2019,55(3): 1988-1999.

9. Xu D, Gao B, Peng W, et al. Thallium pollution in sediments response to consecutive water seasons in Three Gorges Reservoir using geochemical baseline concentrations[J]. Journal of Hydrology, 2018,564: 740-747.

10. Xia J, Xu G, Guo P, et al. Tempo-Spatial Analysis of Water Quality in the Three Gorges Reservoir, China, after its 175-m Experimental Impoundment[J]. Water Resources Management, 2018,32(9): 2937-2954. 